\title{
Near Fatal Asthma after eating deeply Frozen Ice Cream
}

\author{
Maj A Henderson \\ BMedSc, BM, BS, MRCP, RAMC \\ Senior Specialist in Medicine \\ Cambridge Military Hospital
}

SUMMARY: Case report of catastrophic asthma in a young women with hitherto mild asthma following the ingestion of deeply frozen ice cream.

\section{Introduction}

Asthma has many known trigger factors but the ingestion of cold food in this regard received little attention. There are no reports of sudden near fatal asthma brought on by such a trigger. The case reported illustrates yet another potential cause for sudden out of hospital death in otherwise stable asthmatics.

\section{Case Report}

A women aged 20 with a long history of mild asthma, requiring only occasional puffs of salbutamol, was admitted with an attack of fulminating asthma. She had been well on the day of admission and had not required her Ventolin inhaler. She had hurriedly consumed a quantity of deeply frozen ice cream straight from the deep freeze. She had enjoyed the same ice cream many times without ill effects but had never eaten it deeply frozen. Within five minutes of eating the ice cream she felt tight chested and wheezy. The symptoms rapidly progressed over the next five to ten minutes and she became extremely distressed and cyanosed, and was thought by her father to have stopped breathing. He gave her the kiss of life and artificial ventilation was continued in the ambulance. On arrival at the Cambridge Military Hospital she was deeply cyanosed but breathing spontaneously. Her blood pressure was $160 / 70$, heart rate 130 beats per minute sinus rhythm. Auscultation of the chest revealed numerous high pitched rhonchi. She was given high flow oxygen by mask, intravenous aminophylline $250 \mathrm{mg}$, intravenous hydrocortisone $100 \mathrm{mg}$ and salbutamol by nebulizer with good effect. Her chest $\mathrm{x}$-ray showed overinflated lungfields but was otherwise unremarkable. After initial resuscitation her arterial $\mathrm{PO}_{2}$ was $70.8 \mathrm{~mm}$ of mercury. She was then transferred to the intensive care unit and given aminophylline by mouth, salbutamol by nebulizer and hydrocortisone intravenously $100 \mathrm{mg} 4$ hourly. Improvement was rapid and by the next day her peak flow was $340 \mathrm{~L} / \mathrm{min}$ rising to $490 \mathrm{~L} / \mathrm{min}$ after salbutamol. The intravenous hydrocortisone was discontinued and prednisolone $40 \mathrm{mg}$ daily by mouth commenced.
The latter was withdrawn gradually over the following week. She was discharged on Intal, Vento- $\vec{\omega}$ lin, Becotide inhalers - the latter being subsequentlye withdrawn. Her current therapy is regular Intal and occasional Ventolin.

While in hospital two challenge tests were carried out in an attempt to determine the mechanism of the acute attack. Both tests were carried out whileo she was still taking oral prednisolone $20 \mathrm{mg}$ daily

The first test comprised eating partially thawed cream of the same type and flavour as that which? caused initial symptoms. Her peak flow fell frogn $510 \mathrm{~L} / \mathrm{min}$ to $440 \mathrm{~L} / \mathrm{min}$. The next day she was giverng a quantity of crushed ice to swallow. Within ten foc fifteen minutes her peak flow had fallen from 500e $k$ $\mathrm{min}$ to $200 \mathrm{~L} / \mathrm{min}$ and this was associated with appearance of distressing wheezy dyspnoea.

A second ice stress test was carried out subs quently when her only therapy was Intal. The resu通 are shown in Table 1.

It can be seen that there was a rapid and pro.o gressive fall in $\mathrm{FEV}_{1}$ over a period of 15 minuteso associated with subjective dyspnoea and wheeze. Theo bronchospasm was rapidly reversed by inhaled sal $\overrightarrow{\overrightarrow{0}}$ butamol.

Table I

Results of second ice stress test

\begin{tabular}{lccc}
\hline & FEV $_{1}$ & FVC & FEV \\
& $3.5 \mathrm{~L}$ & $3.5 \mathrm{~L}$ & 1 \\
\hline $\begin{array}{l}\text { Control } \\
10 \text { minutes after } \\
\text { ingesting ice }\end{array}$ & $2.5 \mathrm{~L}$ & $3.2 \mathrm{~L}$ & 0.78 \\
$\begin{array}{l}15 \text { minutes after } \\
\text { ingesting ice }\end{array}$ & $1.7 \mathrm{~L}$ & $3.1 \mathrm{~L}$ & 0.55 \\
$\begin{array}{l}\text { 20 minutes after } \\
\text { ingesting ice }\end{array}$ & $2.2 \mathrm{~L}$ & $3.3 \mathrm{~L}$ & 0.66 \\
Post Salbutamol & $3.1 \mathrm{~L}$ & $4.5 \mathrm{~L}$ & 0.88 \\
\hline
\end{tabular}

\section{Discussion}

There seems little doubt that but for the immed م iate first aid rendered by her father, this girl wouldw 
have died at home. Sudden death in young asthmatics remains a tragic, if relatively, uncommon problem ${ }^{1}$. Many have not noticed significant worsening of their symptoms before the fatal episode and death, when it occurs, is usually unexpected and often happens before the patient can receive medical aid. The aetiology is probably polyfactorial and can no longer be attributed simply to inhaled bronchodilators. Autopsy commonly reveals possible bronchiolar plugging by tenacious mucus. In this case there appeared to be two possible explanations for the sudden catastrophic bronchospasm. The first was an anaphylactic reaction to the constituents of the ice cream itself. Against this however is the fact that she had eaten identical ice cream many times before without any ill effects, and that she showed no tendency to anaphylaxis on re-challenging although this must be interpreted in the context of at least partial protection by oral steroids. The second and more probable explanation was cold induced asthma. It has been long known that cold air worsens asthmatic symptoms and this girl had noticed previously that on going from a warm room into cold air, she tended to wheeze. Cooling of the face ${ }^{2}$ and of the airways ${ }^{3}$ has been shown to produce bronchospasm. In this case the presence of deeply frozen ice cream in the mouth would certainly cause significant airways cooling. This might itself be sufficient to trigger off severe bronchospasm. Alternatively, cooling of the mouth, oesophagus and stomach might by a vagal mechanism have induced severe bronchospasm. Although this remains somewhat speculative there is evidence of bronchial hyperactivity in response to autonomic factors in patients with obstructive airways disease $e^{4}$. The time course of the bronchospasm which developed after eating the deeply frozen ice cream was similar to that demonstrated during the crushed ice test and is identical to that induced experimentally in asthmatics on inhaling cold air ${ }^{5}$.

The case illustrates how devastatingly quickly asthma can develop and shows a further possible mechanism for sudden out of hospital death in asthmatics. From the therapeutic point of view it is disturbing to note that the progression of the bronchospasm to hypoxia induced respiratory arrest was in this case too rapid to allow effective medical therapy (there can be little doubt that the girl was saved by the prompt action of her father at home) and that neither pre-treatment of high dose oral steroids, nor with Intal, prevented the gross increase in airways resistance induced by the ingestion of crushed ice. Clearly patients with potentially unstable asthma who have been identified by their past behaviour as being at risk to rapidly progressive and severe exacerbation should be given free and easy access to the local hospital, in a similar fashion to that currently used for patients with suspected myocardial infarction. The patient and the general practitioner both need to have a very low threshold for hospital admission. In addition any obvious precipitating factors, if they can be identified, should be avoided and the patient should be given a supply of oral prednisolone at home which can be started immediately if alarming symptoms develop.

\section{REFERENCES}

1 OGILvie A G. Asthma: A study on prognosis of 1000 patients. Thorax 1962; 17: 183-189.

2 Josenhans W.T, Melville G N and Ulmer W $T$. The effect of facial cold stimulation on airways conductance in healthy man. Can J Physiol Pharmacol 1969; 47: 543-457.

3 Strauss R H, McFadden Jr E R, Ingram Jr R H AND JAEGER J J. Enhancement of exercise induced asthma by cold air. New Eng J Med 1977; 297: 743-747.

5 Simonsson B G, Jacobs $F$ M and Nadel $J$ A. Role of autonomic nervous system and the cough reflex in the increased responsiveness of airways in patients with obstructive airways disease. J Clin Invest 1967; 46: 1812-1818.

5 RAMSEY J M. Time course of bronchoconstructive response in asthmatic subjects to reduced temperature. Thorax 1977; 32: 26-28. 